Original Research Paper

\title{
Feasibility of Non-destructive and Portable Determination for Carrot Quality based on Acoustic Signals
}

\author{
Wangyou Zhang, Mingjin Cai, Qiwei Guo, Jialing Huang and Yang Liu* \\ School of Biology and Food Engineering, Changshu Institute of Technology, Changshu, China
}

\author{
Article history \\ Received: 19-02-2021 \\ Revised: 12-05-2021 \\ Accepted: 18-05-2021 \\ *Corresponding Author: \\ Yang Liu \\ School of Biology and Food \\ Engineering, Changshu \\ Institute of Technology, \\ Changshu, China \\ E-mail: liuyang84@126.com
}

\begin{abstract}
To discuss the feasibility of non-destructive determination method for carrot quality based on the acoustic signal, Pearson correlations between the acoustic eigenvalues and the main compositions of carrot were performed. It indicated that the water content, polysaccharide content and pectin content of carrot were all significantly $(P<0.01)$ correlated with waveform index and sound intensity of acoustic eigenvalues in the timedomain and TE in the range of 2-3, 3-4, 4-5, 5-6, 6-7, 7-8 and 8-9 kHz. Through PCA analysis, 9 eigenvalues with good correlation can be reduced into two principal component factors. The acoustic signals knocked by the self-made signal collection platform could be a new nondestructive testing technology for quality evaluation of carrots. These results will provide essential information to determine the food attributes of agro-products through acoustic signals.
\end{abstract}

\section{Keywords: Carrot, Quality, Non-Destructive Method, Acoustic Signal}

\section{Introduction}

Agro-products quality is the critical index chosen by consumers and is always evaluated by chemical or instruments analytical methods. However these methods are time-consuming and destructive and it is difficult to detect one by one in grading or selling, especially for the retailers in the supermarket. Destructive methods cannot test the agro-products that are not sold in supermarkets, only can be sold after being graded again by sensory evaluation. Hence, a measurement method with non-destruction, portable, low-cost and fast is an urgent need for retailers or ordinary consumers. However, there is lots of research about non-destructive methods for detecting agro-products quality, such as infrared spectrum, nuclear magnetic resonance, computer vision, etc. (Kutsanedzie et al., 2019; Nicolaï et al., 2014). They are more suitable for the agricultural or food industry due to the disadvantages of high cost and sufficient space. As an alternative non-destructive method, the acoustic vibration method possesses the potential to be a measurement method with portable, lowcost and fast (Zhang et al., 2018a).

Generally, there are three parts of the excitation module, signal acquisition and signal processing during the acoustic vibration method (Zhang et al., 2018b). Firstly, in the excitation module, the sample was excited by the excitation signal. The excitation methods mainly include the impact and forced way, which need different effects or forced devices (Taniwaki and Sakurai, 2010).
The hammer or stick is the standard device for the impact method, but it is challenging to provide repeatable excitation for agro-products quality measurement. The pendulum is another common device that can give repeatable excitation by releasing it at the same angle. These excitation devices possess the advantages of simplicity, low-cost and convenience, suitable for portable and non-destructive detection for agro-products (Zhang et al., 2018a). The electrodynamic vibrator was often used for the forced method to obtain excitation for agro-products measurement (Abbaszadeh et al., 2013; Terasaki et al., 2001). The random and swept sine wave excitations in a wide frequency range were often used in agro-products measurement (Abbaszadeh et al., 2014; Muramatsu et al., 1999; 1997; Taniwaki and Sakurai et al., 2010). The forced vibration method possesses good repeatability, yet it was time-consuming and inconvenient for agro-products measurement. Therefore, the pendulum may be a sound excitation module for the non-destructive measurement of agroproducts. Secondly, in the acquisition module, the response signal was collected via contact or non-contact sensors and computer. The contact sensors, such as the acceleration pickup and piezoelectric sensor, were directly contacted with the surface of agro-products. However, the attachment of contact sensor may affect the original vibration of sample or cause damage to the surface of agro-products (Taniwaki et al., 2009; Zhang et al., 2018b). The non-contact sensors, including microphone 
and Laser Doppler Vibrometer (LDV), were not contacted with the surface of agro-products and has been used in many studies for agro-products measurement (Chen et al., 1992; Li et al., 2018; Liu et al., 2020a; Muramatsu et al., 1999; 1997; Murayama et al., 2006). Compared with a microphone, LDV has more accuracy and stability. Nevertheless, the investment of LDV was high and a strong and stable reflected laser beam must be provided (Zhang et al., 2018a; 2015a-b). The microphone has been widely in some studies as a non-contact sensor for the advantages of portability, fast and low-cost. Instead, the response signal obtained by the microphone was easily affected by ambient noise. (Chen et al., 1992; Liu et al., 2015; 2017; 2020b). Therefore, if a microphone is selected as a non-contact sensor to achieve non-destructive measurement of agricultural products, eliminating the impact of environmental noise will be a key issue. Lastly, in the signal processing module, Fourier Transforms (FT) was the most commonly used method for analyzing the response signals. It can reflect the internal relationship between timedomain and frequency-domain of stationary signals. Even so, it cannot show the emergence and disappearance time of the frequency signal (Heuchel et al., 2018; Do, 2018). Hilbert Huang Transform (HHT) is another useful method for analyzing the response signals. Compared with FT, HHT was not constrained by the uncertainty principle and the realtime change of frequency energy can be observed in time domain (Huang et al., 1998; Huang et al., 1999).

Carrot (Daucus carota) is one of the common vegetables in the world. In this study, the main objective was to investigate the feasibility of non-destructive and portable measurements for carrot quality based on acoustic signals for retailers in supermarkets or consumers. The impact method of acoustic signal was pendulum method. The microphone was chosen as non-contact sensors for collecting acoustic signals. Meanwhile, the acoustic signal processing method of time-domain and HHT were combined to analyze the signals of portable signals. The carrot quality indices, including water, sugar and pectin, were detected and their correlations with the eigenvalues of acoustic signals were analyzed. These findings would provide a new portable non-destructive detection method of acoustic signal for agro-products.

\section{Materials and Methods}

\section{Samples}

Totally 28 fresh carrots (diameter $4-5 \mathrm{~cm}$, length 18$20 \mathrm{~cm}$ ) without damage were bought from a local market in Jilin City, Jilin Province, China, in March 2018.

\section{Acquisition of Acoustic Signal}

The acoustic signal acquisition platform was designed to simulate a pendulum for collecting the acoustic signals from apples via steel ball knocking (Zhang et al., 2018b).
The acquisition platform was composed of platform, track, fixing device, rod, steel ball (diameter $5 \mathrm{~cm}, 50 \mathrm{~g}$ ), microphone (AT8033, Audio-Technica, Tokyo, Japan) and computer (Aspire 4736ZG, Acer, Taipei, Taiwan, China). The platform was placed in a relatively quiet room with echoic decorative materials for avoiding ambient noise. The sponge also enclosed the platform surface and the fixing devices to eliminate noise from the experiment. The microphone used as non-contact sensors was connected to the computer and placed $2 \mathrm{~cm}$ away from the sample's equatorial axis (Liu et al., 2020b). The microphone is a directional microphone that mainly collects the sound signals in the vertical direction to prevent environmental noise interference. The software's acoustic signal was recorded (Cool Edit Professional; Adobe Systems, Los Altos, CA, USA) with a sampling frequency of 44,100 Hz.

\section{Acoustic Eigenvalues of the Acoustic Signal in Time-Domain and Frequency-Domain}

The acoustic signals as-acquired were denoised by a wavelet denoising method. Our early studies confirmed the sensory crispness of carrots was significantly related to waveform index and acoustic energy (Liu et al., 2015; 2017). The formula of waveform index and acoustic energy were listed in Table 1. According to the HilbertHuang transform (Huang et al., 1998), the original signal $X(t)$ can be expressed as the sum of IMFs and a residual. The formula was also listed in Table 1 . This equation enables us to represent the time and the instantaneous frequency in a two-dimensional plot. This frequency-time distribution is designated as Hilbert spectra. Preliminary tests show the frequency of acoustic signals acquired from this method varies within 1-10000 Hz. This result is slightly different from our previous study on the relationship between sensory brittleness and acoustical signals, mainly because of differences in probes and types of rupture between the reviews (Liu et al., 2015). Through the HHT method, the frequency energy at different frequency-domains could be well extracted. From the Hilbert spectrum, we can determine the energy at each frequency range. Based on the experimental dispart the relative energy of acoustic signals at each frequency range, each sample was sent into eigenvalue extraction. The frequency-domain eigenvalues showed the frequency band of acoustic signals was concentrated at $0-10 \mathrm{kHz}$. Therefore, the frequency range was divided into ten divisions of $0-1$, 1-2, 2-3, 3-4, 4-5, 5-6, 6-7, 7-8, 8-9, 9-10 kHz.

\section{Determination of Water Content}

According to the National Standard of China, the water content was determined by the weight difference method (Liu et al., 2020a). 


\section{Determination of Polysaccharide Content}

\section{Standard Curve of Glucose}

Firstly, $20 \mathrm{mg}$ of analytically pure glucose was correctly weighed, dissolved in distilled water and diluted to a $500 \mathrm{~mL}$ volumetric flask. Then the glucose solution of $0,0.5,1,1.5$ and $2 \mathrm{~mL}$ were added into the five test tubes and then diluted with distilled water to $2 \mathrm{~mL}$. Each tube was then added with $1 \mathrm{~mL}$ of $6 \%$ phenol solution and $5 \mathrm{~mL}$ of concentrated sulfuric acid solution. The tubes were shaken evenly, cooled and colored at room temperature for $30 \mathrm{~min}$. Then the absorbance at $490 \mathrm{~nm}$ was measured. A blank control was set by using $2.0 \mathrm{~mL}$ of distilled water instead. A standard glucose curve was plotted with glucose concentration as the $\mathrm{X}$-axis and absorbance as the Y-axis (Liu et al., 2020a).

\section{Measurement of Carrot Polysaccharides}

Carrot polysaccharides were extracted by water extraction and alcohol precipitation method and then detected by phenol sulfuric acid method. Specifically, carrot samples stored for 0 (fresh), 5, 10 and 15 days were crushed and weighed (each $15 \mathrm{~g}$ ). Each sample was added with an appropriate amount of anhydrous ethanol and then put into a water bath at $50^{\circ} \mathrm{C}$ for $20 \mathrm{~min}$. After filtering, the residues were added with $450 \mathrm{~mL}$ of distilled water, immerse-extracted in a water bath at $60^{\circ} \mathrm{C}$ for $6-8 \mathrm{~h}$ and then leached. The filtrates were concentrated in a rotational evaporimeter to $1 / 5$ of the original volume. Then after centrifugation at $4000 \mathrm{r} / \mathrm{min}$ for $20 \mathrm{~min}$, the supernatants were collected and added with four volumes of anhydrous ethanol. After placement in a refrigerator for $24 \mathrm{~h}$ for precipitation, the three polysaccharide samples were taken out and centrifuged again for $20 \mathrm{~min}$. The precipitates and the dried carrot polysaccharide crude samples were weighed, dissolved also and diluted to $100 \mathrm{~mL}$. Each sample $(1 \mathrm{~mL})$ was diluted to $2 \mathrm{~mL}$. To each tube, $1 \mathrm{~mL}$ of $6 \%$ phenol solution and $5 \mathrm{~mL}$ of concentrated $\mathrm{H}_{2} \mathrm{SO}_{4}$ was added and colored at room temperature for $30 \mathrm{~min}$. Then the absorbance at $490 \mathrm{~nm}$ was measured. A blank control was set by using $2.0 \mathrm{~mL}$ of distilled water instead.

\section{Determination of Pectin}

The pectin's determination method was modified based on the agro-product industry standard-Determination of pectin content in fruits and their products by Spectrophotometry (Liu et al., 2020a).

\section{Standard Curve of Galacturonic Acid}

Galacturonic acid standard solution of $0,20.0,40.0$, $60.0,80.0$ and $100.0 \mu \mathrm{g} / \mathrm{mL}$ were prepared, $1.0 \mathrm{~mL}$ of galacturonic acid standard solution with different concentration were accurately absorbed into a $25 \mathrm{~mL}$ stoppered test tube, $6 \mathrm{~mL}$ of concentrated sulfuric acid was added respectively. The solution's test tubes were shaken, heated in a boiling water bath for $20 \mathrm{~min}$ and then cooled. The tubes were added $0.5 \mathrm{~mL}$ of $0.15 \%$ carbazole ethanol and were placed in the dark for $2 \mathrm{~h}$. The absorbance of the tubes was measured at $530 \mathrm{~nm}$. A standard galacturonic acid curve was plotted with galacturonic acid concentration concentration as the Xaxis and absorbance as the $\mathrm{Y}$-axis.

\section{Determination of Carrot Pectin}

The carrots should be Pre-treated as follows: The carrots were washed and sliced and they were boiled in boiling water for $4 \mathrm{~min}$. Then the samples were dried at $65^{\circ} \mathrm{C}$ for $12 \mathrm{~h}$.

The pre-treated samples of $2.5 \mathrm{~g}$ were weighed and placed in a $100 \mathrm{~mL}$ conical flask. Then $95 \%$ ethanol of 40 $\mathrm{mL}$ was added and heated in a boiling water bath for 30 min. After filtration, the precipitation was taken in a 100 $\mathrm{mL}$ beaker and added $30 \mathrm{~mL}$ of water to heat for $30 \mathrm{~min}$ in a $50^{\circ} \mathrm{C}$ water bath. Next, fix the volume of solution to $100 \mathrm{~mL}$, which is the sample's pectin solution. Pectin solution of 0.1 $\mathrm{mL}$ was diluted with $0.9 \mathrm{~mL}$ of water and the absorbance of the mixture was determined according to the determination method of the galacturonic acid standard curve. The calculation of pectin content is shown in the formula:

$$
\omega(\%)=\frac{\rho \times V}{m \times 1000} \times 100
$$

Where:

$\Omega=$ The content of pectin in carrots, $\%$

$\rho=$ The content of galacturonic acid found from the standard curve, $\mu \mathrm{g} / \mathrm{mL}$

$V=$ The constant volume of pectin precipitation, $\mathrm{mL}$

$m=$ Sample weight, $\mathrm{g}$

\section{Principle Component Analysis}

Principle Component Analysis (PCA) is the standard method to reduce variables that correlated to each other.

PCA can compress the original lots of variables into several new variables (Liu et al., 2020b). Many acoustic eigenvalues were studied in this study, PCA will be used to condense the acoustic eigenvalues' dimension.

\section{Statistical Analysis}

All data of carrot polysaccharide content and acoustic signal characteristics were analyzed by one-way Analysis of Variance (ANOVA) on SPSS for Windows, version rel. 10.0.5, 1999 (SPSS Inc., Chicago, IL, USA). Correlations among the means were identified using the Pearson correlation test. All the programs for the extraction of acoustic signal characteristics were written on Matrix Laboratory (Matlab; Math Works Inc., Natick, MA, USA). 
Table 1: Acoustic signal eigenvalues in Time-domain and Frequency-domain

\begin{tabular}{lll}
\hline Acoustic signal eigenvalues & Calculation formula & Connotation \\
\hline Waveform index (Time-domain) & $Y_{2}=\sum_{n=0}^{N-1}|x(i)|^{2} / \sqrt{1 / N\left(\sum_{n=0}^{N-1}|x(i)|\right)}$ & The ratio of acoustical signal energy and the root-mean-square of amplitude \\
Sound intensity (dB) (Time-domain) & $E=\sum_{n=0}^{N-1}|x(i)|^{2}$ & Total energy of sampling points of discrete acoustic signal \\
Total energy in each frequency & $E s=10 \log \sum_{i=1}^{n} S i$ & Total energy of different frequency is calculated by HHT \\
domain (dB) (Frequency-domain) & &
\end{tabular}

\section{Results}

\section{The Standard Curve of Glucose and Galacturonic Acid}

The standard curves of glucose and galacturonic acid are shown in Fig. 1. The glucose curve equation was $y=$ $5.7729 x+0.0005\left(R^{2}=0.9994\right)$, the standard curve has a good correlation between the concentration of glucose 0 $0.12 \mathrm{mg} / \mathrm{mL}$ and absorbance (Fig. 1A). The equation of the galacturonic acid curve was $y=0.0045 \times-0.0035,\left(R^{2}\right.$ $=0.9965)$, the standard curve has a good correlation between the concentration of glucose $0-100 \mu \mathrm{g} / \mathrm{mL}$ and absorbance (Fig. 1B).

\section{Changes of Main Carrot Compositions and Acoustic Eigenvalues}

The changes of main compositions, including water, polysaccharide and pectin, were shown in Table 2 . The water and pectin content was declined with the prolonging of storage days. The water content of fresh carrots was more than $90.30 \pm 0.18 \%$. With the increase of storage days, the water content of carrots gradually decreased. On the 15 th day of storage, the water content of the carrot fell to about $86.34 \pm 0.30 \%$. The pectin content of fresh carrots was the highest, reaching about $17.58 \pm 0.51 \%$. With the increase of storage days, the pectin content in carrots gradually decreased. The pectin content decreased to about $7.64 \pm 0.32 \%$ on the 15th day. On the contrary, the polysaccharide concentrations slowly rose with the prolonging storage time. The content of polysaccharides in fresh carrots was the lowest. The polysaccharide concentration after $15 \mathrm{~d}$ of storage increased by nearly one-fold compared with fresh samples.

The acoustic eigenvalues in Time-Frequency of carrot were listed in Table 2. Each sample was measured in triplicate. The time-domain and frequency-domain eigenvalues of the carrots both changed to different degrees after storage for a different duration. Waveform index and Sound intensity of Time-domain characteristics showed a rising trend with the extension of storage time. The frequency-domain energy of acoustic signals was concentrated within $0-1 \mathrm{kHz}$, but the frequency-domain energy changed irregularly with the prolonging of storage time. Compared with other frequency-domain ranges, the frequency-domain energy at $1-2$ or $2-3 \mathrm{kHz}$ was also tremendous but changed irregularly. On the contrary, the energy at 2-3, 3-4, 4-5, 5-6, 6-7, 7-8, 8-9, 9-10 kHz was small, which showed specific sensitivity.

Correlations of Main Carrot Compositions with Time-Domain or Frequency-Domain Eigenvalues

Correlations between the main carrot compositions and acoustic signals were analyzed according to Pearson's method by SPSS. The correlation coefficients of main carrot compositions with acoustic signals were illustrated in Table 3 .

As is shown in Table 3, the water content, polysaccharide content and pectin content of carrot were all significantly correlated with waveform index and sound intensity (both $\mathrm{P}<0.01$ ) of acoustic eigenvalues in the time-domain and were significantly correlated $(\mathrm{P}<0.01)$ with TE in the range of $2-3,3-4,4-$ 5, 5-6, 6-7, 7-8 and 8-9 kHz. This result is consistent with previous detection of sugar content in sweet potato based on acoustic signals (Liu et al., 2020).

\section{Principal Component Analysis Based on Eigenvalues of Acoustic Signals}

From Table 3, the water content, polysaccharide content and pectin content of carrot were significantly correlated with nine eigenvalues of acoustic signals, so the Principal Component Analysis (PCA) was adopted to reduce the nine correlated eigenvalues. It can be seen from Fig. 2, the PCA diagrams of water content (Fig. 2A), polysaccharide content (Fig. 2B) and pectin content (Fig. 2C) of carrots were almost identical, without any difference. All the nine eigenvalues of acoustic signals can be reduced into two dimensions. The waveform index and sound intensity constituted PC1, the total energy in the frequency bands of 2-3, 34, 4-5, 5-6, 6-7, 7-8 and 8-9 kHz constituted PC2. 
Wangyou Zhang et al. / American Journal of Biochemistry and Biotechnology 2021, 17 (2): 232.240 DOI: 10.3844/ajbbsp.2021.232.240

Table 2: Main compositions and acoustic eigenvalues in time-frequency of carrots during different storage periods $(\mathrm{N}=28$, average \pm stdv.)

\begin{tabular}{lllll}
\hline & Fresh & 5 days & 10 days & 15 days \\
\hline Water content (\%) & $90.30 \pm 0.18^{\mathrm{a}}$ & $88.99 \pm 0.24^{\mathrm{b}}$ & $87.15 \pm 0.19^{\mathrm{c}}$ & $86.34 \pm 0.30^{\mathrm{d}}$ \\
Polysaccharide content (\%) & $0.70 \pm 0.02^{\mathrm{d}}$ & $0.94 \pm 0.03^{\mathrm{c}}$ & $1.08 \pm 0.08^{\mathrm{b}}$ & $1.39 \pm 0.08^{\mathrm{a}}$ \\
Pectin content (\%) & $17.58 \pm 0.51^{\mathrm{a}}$ & $14.90 \pm 0.17^{\mathrm{b}}$ & $12.72 \pm 0.34^{\mathrm{c}}$ & $7.64 \pm 0.32^{\mathrm{d}}$ \\
Waveform index & $22.14 \pm 6.60^{\mathrm{b}}$ & $30.15 \pm 4.36^{\mathrm{b}}$ & $64.24 \pm 22.55^{\mathrm{a}}$ & $62.69 \pm 7.55^{\mathrm{a}}$ \\
Sound intensity (dB) & $7.19 \pm 1.85^{\mathrm{b}}$ & $7.08 \pm 3.11^{\mathrm{b}}$ & $17.29 \pm 9.14^{\mathrm{a}}$ & $19.99 \pm 5.77^{\mathrm{a}}$ \\
TE0-10 kHz & $91.34 \pm 42.95^{\mathrm{b}}$ & $33.71 \pm 30.01^{\mathrm{c}}$ & $71.38 \pm 19.22^{\mathrm{bc}}$ & $157.83 \pm 25.34^{\mathrm{a}}$ \\
TE1-2 kHz & $3.88 \pm 2.14^{\mathrm{b}}$ & $1.45 \pm 0.66^{\mathrm{c}}$ & $1.95 \pm 0.63^{\mathrm{c}}$ & $6.17 \pm 0.40^{\mathrm{a}}$ \\
TE2-3 kHz & $0.93 \pm 0.46^{\mathrm{bc}}$ & $0.56 \pm 0.59^{\mathrm{c}}$ & $1.23 \pm 0.26^{\mathrm{ab}}$ & $1.61 \pm 0.37^{\mathrm{a}}$ \\
TE3-4 kHz & $0.33 \pm 0.22^{\mathrm{c}}$ & $0.21 \pm 0.07^{\mathrm{c}}$ & $0.81 \pm 0.20^{\mathrm{b}}$ & $1.02 \pm 0.07^{\mathrm{a}}$ \\
TE4-5 kHz & $0.21 \pm 0.17^{\mathrm{c}}$ & $0.29 \pm 0.28^{\mathrm{c}}$ & $0.61 \pm 0.17^{\mathrm{b}}$ & $1.09 \pm 0.32^{\mathrm{a}}$ \\
TE5-6 kHz & $0.25 \pm 0.19^{\mathrm{c}}$ & $0.28 \pm 0.19^{\mathrm{c}}$ & $0.61 \pm 0.12^{\mathrm{b}}$ & $1.11 \pm 0.21^{\mathrm{a}}$ \\
TE6-7 kHz & $0.25 \pm 0.18^{\mathrm{b}}$ & $0.22 \pm 0.11^{\mathrm{b}}$ & $0.36 \pm 0.06^{\mathrm{b}}$ & $1.51 \pm 0.32^{\mathrm{a}}$ \\
TE7-8 kHz & $0.17 \pm 0.14^{\mathrm{b}}$ & $0.12 \pm 0.06^{\mathrm{b}}$ & $0.23 \pm 0.06^{\mathrm{b}}$ & $1.19 \pm 0.29^{\mathrm{a}}$ \\
TE8-9 kHz & $0.10 \pm 0.09^{\mathrm{b}}$ & $0.10 \pm 0.04^{\mathrm{b}}$ & $0.16 \pm 0.03^{\mathrm{b}}$ & $0.50 \pm 0.12^{\mathrm{a}}$ \\
TE9-10 kHz & $0.05 \pm 0.04^{\mathrm{c}}$ & $0.06 \pm 0.03^{\mathrm{bc}}$ & $0.14 \pm 0.03^{\mathrm{b}}$ & $0.38 \pm 0.14^{\mathrm{a}}$ \\
\hline
\end{tabular}

Table 3: Correlations of between main compositions of carrot and acoustic eigenvalues $(\mathrm{N}=28)$

\begin{tabular}{|c|c|c|c|c|c|c|c|c|c|c|c|c|c|c|c|}
\hline & WAC (\%) & POC (\%) & PEC (\%) & WI & SI & $0-1 \mathrm{kHz}$ & $1-2 \mathrm{kHz}$ & $2-3 \mathrm{kHz}$ & $3-4 \mathrm{kHz}$ & $4-5 \mathrm{kHz}$ & $5-6 \mathrm{kHz}$ & $6-7 \mathrm{kHz}$ & $7-8 \mathrm{kHz}$ & $8-9 \mathrm{kHz}$ & $9-10 \mathrm{kHz}$ \\
\hline WAC (\%) & 1 & $-0.932^{* *}$ & $0.942^{* *}$ & $-.839^{* *}$ & $-.710^{* *}$ & -0.275 & -0.122 & $-0.482^{* *}$ & $-0.781^{* 3}$ & $-0.762^{* *}$ & $-0.784^{* *}$ & $-0.646^{* *}$ & $-0.633^{* *}$ & $-0.669^{* *}$ & -0.231 \\
\hline POC (\%) & & 1 & $-0.969^{* *}$ & $.778 * *$ & $.758 * *$ & $0.413^{*}$ & 0.221 & $0.509^{* *}$ & $0.737^{* *}$ & $0.848^{* *}$ & $0.860^{* *}$ & $0.793^{* *}$ & $0.788^{* *}$ & $0.765^{* *}$ & 0.127 \\
\hline $\operatorname{PEC}(\%)$ & & & 1 & $-.740^{* * *}$ & $-.671^{* *}$ & $-0.455^{*}$ & 0.306 & $-0.535^{* *}$ & $-0.779^{* *}$ & $-0.830^{* *}$ & $-0.861^{* *}$ & $-0.823^{* *}$ & $-0.813^{* *}$ & $-0.823^{* *}$ & -0.173 \\
\hline WI & & & & 1 & $.901 * *$ & 0.27 & 0.122 & $.483^{* *}$ & $.711^{* *}$ & $.694 * *$ & $.694 * *$ & $.513^{* *}$ & $.466^{*}$ & $.484 * *$ & 0.29 \\
\hline SI (dB) & & & & & 1 & $.404 *$ & 0.208 & $.505^{* *}$ & $624 * *$ & $.704 * *$ & $695^{* *}$ & $.531 * *$ & $.576^{* *} *$ & $.511^{* *}$ & 0.178 \\
\hline TE $0-10 \mathrm{kHz}$ & & & & & & 1 & $0.656^{* *}$ & $0.645^{* *}$ & $0.519^{* *}$ & $0.601^{* *}$ & $0.659^{* *}$ & $0.660^{* *}$ & $0.744^{* *}$ & $0.697^{* *}$ & -0.151 \\
\hline TE1-2 kHz & & & & & & & 1 & $0.518^{* *}$ & 0.276 & $0.406^{*}$ & $0.413^{*}$ & $0.584^{* *}$ & $0.560^{* *}$ & $0.514^{*}$ & -0.127 \\
\hline TE2-3 kHz & & & & & & & & 1 & $0.541^{* *}$ & $0.758^{* *}$ & $0.682^{* *}$ & $0.561^{* *}$ & $0.624^{* *}$ & $0.661^{* *}$ & -0.057 \\
\hline TE3-4 kHz & & & & & & & & & 1 & $0.749^{* *}$ & $0.877^{* *}$ & $0.660^{* *}$ & $0.702^{* *}$ & $0.752^{* *}$ & 0.326 \\
\hline TE5-6 kHz & & & & & & & & & & & 1 & $0.825^{* *}$ & $0.876^{* *}$ & $0.875^{* *}$ & 0.180 \\
\hline TE6-7 kHz & & & & & & & & & & & & 1 & $0.890^{* *}$ & $0.848^{* *}$ & -0.015 \\
\hline TE7-8 kHz & & & & & & & & & & & & & 1 & $0.964^{* *}$ & -0.031 \\
\hline TE8-9 kHz & & & & & & & & & & & & & & 1 & 0.024 \\
\hline TE9-10 kHz & & & & & & & & & & & & & & & 1 \\
\hline
\end{tabular}

* refers to $P<0.05$; $* *$ refers to $P<0.01$. WAC: Water Content; POC: Polysaccharide Content; PEC: Pectin Content; WI: Waveform Index

SI: Sound Intensity(dB); TE: Total Energy of different frequency bands

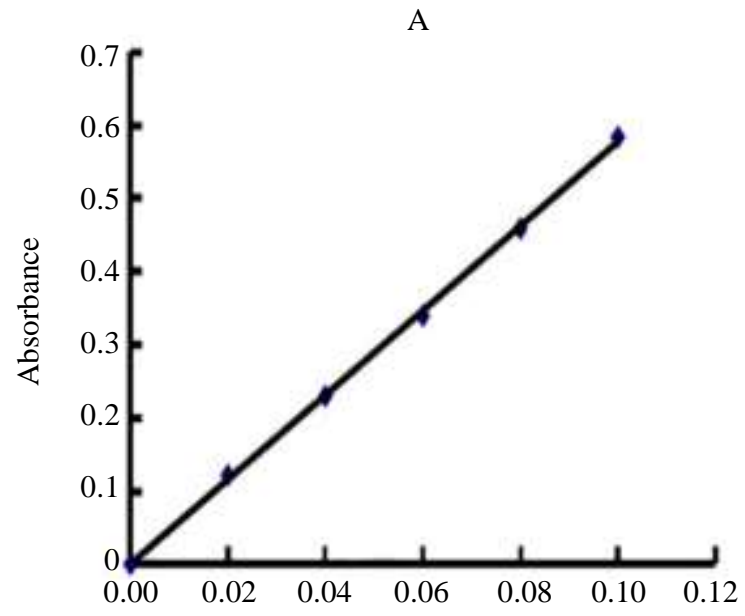

Concentration of glucose $(\mathrm{mg} / \mathrm{ml})$
B

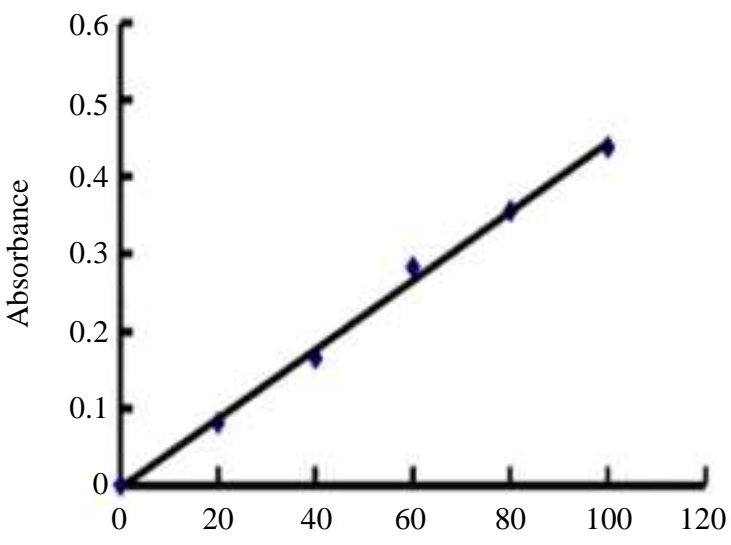

Concentration of galacturonic $(\mu \mathrm{g} / \mathrm{ml})$

Fig.1: Stand curve of glucose (A) and galacturonic acid (B) 
A

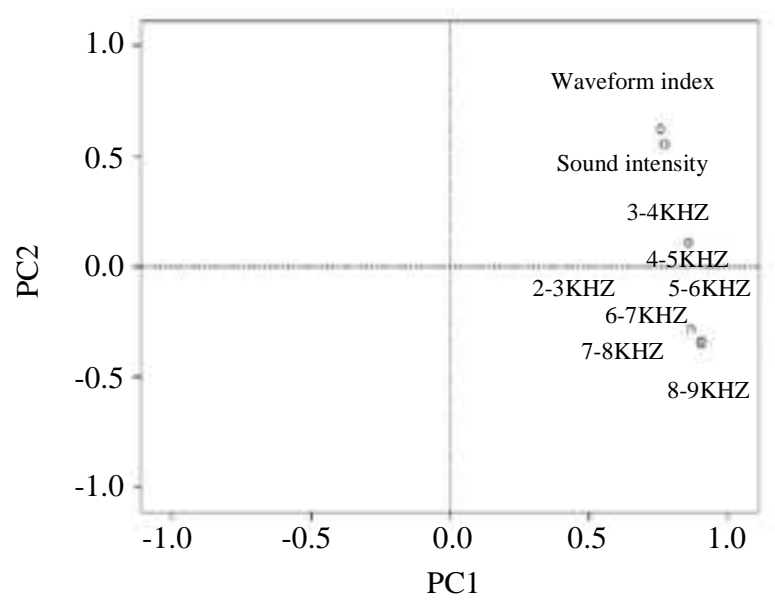

B

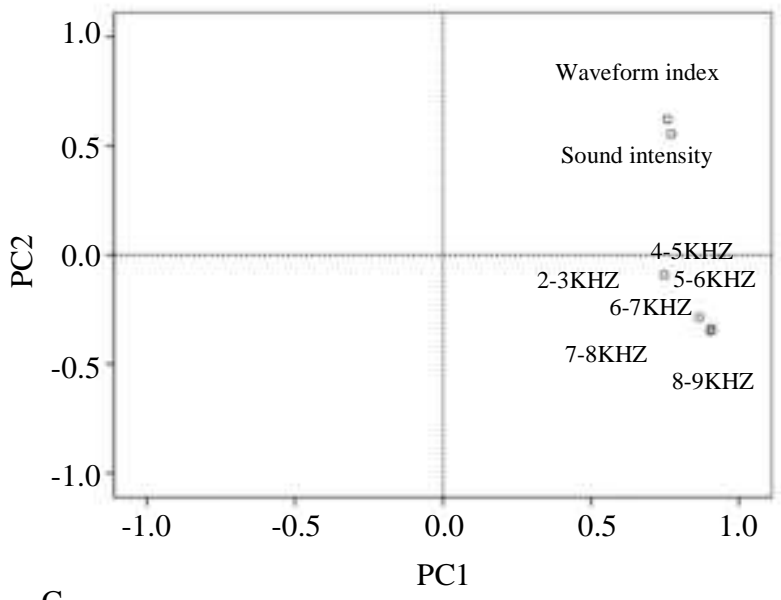

$\mathrm{C}$

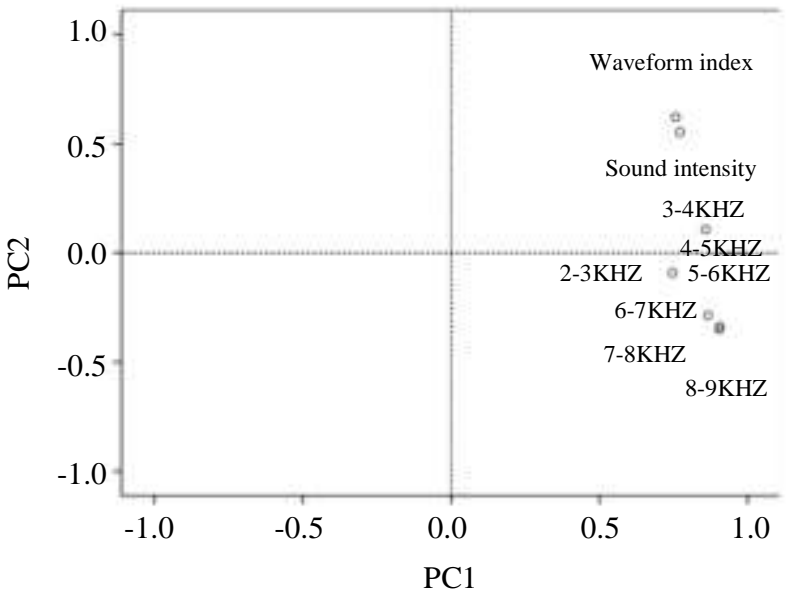

Fig. 2: PCA Charts of acoustic eigenvalues correlated with water (A), polysaccharide (B) and pectin (C) in the Time and Frequency domain

\section{Discussion}

The reason of the changes of main compositions may be that the respiration of carrots is more active during the shelf-life (Shibairo et al., 1997; 2002). Since pectin is the main component of the cell wall, postharvest carrots' storage time is closely related to pectin (Paniagua et al., 2017). With the longer storage time of carrots, pectin was hydrolyzed gradually by pectinase and the content of pectin decreased gradually. The increase of polysaccharide content may be due to other macromolecular substances in carrot, if gum, macromolecular carbohydrate, fat and other substances are continuously decomposed into small molecules of reducing sugar with the participation of related biological enzymes (Goulas et al., 2014). In contrast, the characteristic value of the sound signal did not show a special regular change, which is similar to the results of our previous research (Liu, 2015, 2020a).

Limited by the test time and personnel, this study did not analyze many samples to build an evaluation model for carrot quality. However, the above results confirmed that it is feasible to evaluate carrot quality based on the knocking vibration acoustic signal. Since the technic of the acoustic signal is applied in food quality evaluation (Drake, 1963; 1965), there is still no unified determination method for food quality evaluation based on technic of the acoustic signal. Besides, the different processing methods of acoustic signals, such as Time-domain theory, FT, Wavelet transform and HHT, have been used to analyze the correlations between the food quality attributes and the acoustic eigenvalues (Conde et al., 2007; Liu et al., 2015; Taniwaki and Sakurai, 2010; Wang et al., 2018). In the previous study, we have found that many acoustic eigenvalues processed by Time-domain and HHT correlated with the firmness, crispness and sugar content of some agricultural products (Liu et al., 2015; 2017; $2020 b)$. Hence, in order to explore the feasibility of a nondestructive determination method for carrot quality based on acoustic signals, the acoustic eigenvalues processed by the combination of Time-domain and HHT were chosen 
to analyze the correlations with water content, polysaccharide content and pectin content. The pendulum method was used to be the impact method, which has the advantages of simplicity, low-cost and convenience for food evaluation. The 2 principal components by PCA in this study may be helpful for the non-destructive determination method for carrot quality based on acoustic signals.

\section{Conclusion}

Vibration acoustic signals acquired through the pendulum method has been proved to possess potential application value in non-destructive testing of agricultural products. The sound signal processing method used in combination with Time-domain and HHT has proved to be an effective method for analyzing carrot portable sound signals. The main compositions of carrot, including water content, polysaccharide content and pectin content of carrot, were all significantly correlated with waveform index and sound intensity (both $P<0.01$ ) of acoustic eigenvalues in the time-domain and were significantly correlated $(P<0.01)$ with TE in the range of $2-3,3-4,4-$ $5,5-6,6-7,7-8$ and $8-9 \mathrm{kHz}$. These correlated eigenvalues were reduced into two components by PCA. These results may provide essential nondestructive clues for determining the quality of agricultural products through the acoustic signals.

\section{Acknowledgement}

This work was supported by JiLin Institute of Chemical Technology and Changshu Institute of Technology.

\section{Funding Information}

This study was funded by Scientific Research Foundation for Advanced Talents, Changshu Institute of Technology (Grant No. KYZ2020045Q).

\section{Author's Contributions}

Wangyou Zhang: Participated in the whole experiment and also contributed to the interpretation of the results and manuscript preparation.

Mingjin Cai: Participated in the experimental design.

Qiwei Guo: Data collection and processing.

Jialing Huang: Acoustic signal collection.

Yang Liu: Guide experiment, data processing and thesis writing.

\section{Ethics}

All the authors have read and approved the manuscript and no ethical issues involved. This article is original and contains unpublished material.

\section{References}

Abbaszadeh, R., Rajabipour, A., Mahjoob, M., Delshad, M., \& Ahmadi, H. (2013). Evaluation of watermelons texture using their vibration responses. Biosystems Engineering, 115(1), 102-105.

https://doi.org/10.1016/j.jfoodeng.2013.11.020

Abbaszadeh, R., Rajabipour, A., Sadrnia, H., Mahjoob, M. J., Delshad, M., \& Ahmadi, H. (2014). Application of modal analysis to the watermelon through finite element modeling for use in ripeness assessment. Journal of Food Engineering, 127, 80-84. https://doi.org/10.13031/2013.28815

Chen, P., Sun, Z., \& Huarng, L. (1992). Factors affecting acoustic responses of apples. Transactions of the ASAE, 35(6), 1915-1920.

https://elibrary.asabe.org/abstract.asp?aid=28815

Conde, T., Cárcel, J. A., García-Pérez, J. V., \& Benedito, J. (2007). Non-destructive analysis of Manchego cheese texture using impact force-deformation and acoustic impulse-response techniques. Journal of Food Engineering, 82(2), 238-245. https://doi.org/10.1016/j.jfoodeng.2007.01.027

Do, T. S. (2018). The Fourier Transform and Principles of Quantum Mechanics. Applied Mathematics, 9(04), 347-354. https://doi.org/10.4236/am.2018.94026

Drake, B. K. (1963). Food crushing sounds. an introductory study a, b. Journal of Food Science, 28(2), 233-241. https://doi.org/10.1111/j.13652621.1963.tb00190.x

Drake, B. K. (1965). Food crushing sounds: comparisons of objective and subjective data. Journal of Food Science, 30(3), 556-559. https://doi.org/10.1111/j.1365-2621.1965.tb01801.x

Goulas, V., Minas, I. S., Kourdoulas, P. M., Vicente, A. R., \& Manganaris, G. A. (2014). Phytochemical content, antioxidants and cell wall metabolism of two loquat (Eriobotrya japonica) cultivars under different storage regimes. Food chemistry, 155, 227-234. https://doi.org/10.1016/j.foodchem.2014.01.054

Heuchel, F. M., Fernandez-Grande, E., Agerkvist, F. T., $\&$ Shabalina, E. (2018). Active room compensation for sound reinforcement using sound field separation techniques. The Journal of the Acoustical Society of America, 143(3), 1346-1354.

https://doi.org/10.1121/1.5024903

Huang, N. E., Shen, Z., Long, S. R., Wu, M. C., Shih, H. H., Zheng, Q., .. \& \& Liu, H. H. (1998). The empirical mode decomposition and the Hilbert spectrum for nonlinear and non-stationary time series analysis. Proceedings of the Royal Society of London. Series A: Mathematical, Physical and Engineering Sciences, 454(1971), 903-995. https://doi.org/10.1098/rspa.1998.0193 
Huang, N. E., Shen, Z., \& Long, S. R. (1999). A new view of nonlinear water waves: The Hilbert spectrum. Annual review of fluid mechanics, 31(1), 417-457. https://doi.org/10.1146/annurev.fluid.31.1.417

Kutsanedzie, F. Y., Guo, Z., \& Chen, Q. (2019). Advances in nondestructive methods for meat quality and safety monitoring. Food Reviews International, 35(6), 536-562.

Li, B., Cobo-Medina, M., Lecourt, J., Harrison, N., Harrison, R. J., \& Cross, J. V. (2018). Application of hyperspectral imaging for nondestructive measurement of plum quality attributes. Postharvest Biology and Technology, 141, 8-15. https://doi.org/10.1016/j.postharvbio.2018.03.008

Liu, Y., Zhang, T., Zheng, M. Z., Liu, H. M., \& Zhang, Y. (2020a). Relationship between sugar content in sweet potato and vibration acoustic signal eigenvalues. Journal of Food Process Engineering, 43(4), e13359. https://doi.org/10.1111/jfpe.13359

Liu, Y., Cai, M., Zhang, W., Feng, W., Sun, X., Zhang, Y., \& Zhou, H. (2020b). Feasibility of non-destructive evaluation for apple crispness based on portable acoustic signal. International Journal of Food Science \& Technology. https://doi.org/10.1111/ijfs.14861

Liu, Y., Huang, B. Z., Sun, Y. H., Chen, F. Y., Yang, L., Mao, Q., ... \& Zheng, M. Z. (2015). Relationship of carrot sensory crispness with acoustic signal characteristics. International Journal of Food Science \& Technology, 50(7), 1574-1582. https://doi.org/10.1111/ijfs.12808

Liu, Y., Sun, Y. H., Yang, L., Yu, L. B., Mao, Q., Hou, J. M., ... \& Liu, C. (2017). Relationship between carrot firmness with acoustic signal characteristics. Journal of Food Process Engineering, 40(2), e12384. https://doi.org/10.1111/jfpe.12384

Muramatsu, N., Sakurai, N., Wada, N., Yamamoto, R., Takahara, T., Ogata, T., ... \& Nevins, D. J. (1999). Evaluation of fruit tissue texture and internal disorders by laser Doppler detection. Postharvest Biology and Technology, 15(1), 83-88. https://doi.org/10.1016/S0925-5214(98)00062-3

Muramatsu, N., Tanaka, K., Asakura, T., IshikawaTakano, Y., Sakurai, N., Wada, N., ... \& Nevins, D. J. (1997). Critical comparison of an accelerometer and a laser Doppler vibrometer for measuring fruit firmness. HortTechnology, 7(4), 434-438. https://doi.org/10.21273/HORTTECH.7.4.434

Murayama, H., Konno, R., Terasaki, S., Yamamoto, R., \& Sakurai, N. (2006). Nondestructive Method for Measuring Fruit Ripening of 'La France' Pears Using a Laser Doppler Vibrometer. Journal Japan Sociology Hurting Science, 75(1), 79-84. https://doi.org/10.2503/jjshs.75.79
Nicolaï, B. M., Defraeye, T., De Ketelaere, B., Herremans, E., Hertog, M. L., Saeys, W., ... \& Verboven, P. (2014). Nondestructive measurement of fruit and vegetable quality. Annual Review of Food Science and Technology, 5, 285-312. https://doi.org/10.1146/annurev-food-030713-092410

Paniagua, C., Santiago-Doménech, N., Kirby, A. R., Gunning, A. P., Morris, V. J., Quesada, M. A., ... \& Mercado, J. A. (2017). Structural changes in cell wall pectins during strawberry fruit development. Plant Physiology and Biochemistry, 118, 55-63. https://doi.org/10.1016/j.plaphy.2017.06.001

Shibairo, S. I., Upadhyaya, M. K., \& Toivonen, P. M. (2002). Changes in water potential, osmotic potential and tissue electrolyte leakage during mass loss in carrots stored under different conditions. Scientia Horticulturae, 95(1-2), 13-21. https://doi.org/10.1016/S0304-4238(02)00034-1

Shibairo, S. I., Upadhyaya, M. K., \& Toivonen, P. M. A. (1997). Postharvest moisture loss characteristics of carrot (Daucus carota L.) cultivars during short-term storage. Scientia Horticulturae, 71(1-2), 1-12. https://doi.org/10.1016/S0304-4238(97)00077-0

Taniwaki, M., \& Sakurai, N. (2010). Evaluation of the internal quality of agricultural products using acoustic vibration techniques. Journal of the Japanese Society for Horticultural Science, 79(2), 113-128. https://doi.org/10.2503/jjshs1.79.113

Taniwaki, M., Hanada, T., Tohro, M., \& Sakurai, N. (2009). Non-destructive determination of the optimum eating ripeness of pears and their texture measurements using acoustical vibration techniques. Postharvest Biology and Technology, 51(3), 305-310. https://doi.org/10.1016/j.postharvbio.2008.08.004

Terasaki, S., Wada, N., Sakurai, N., Muramatsu, N., Yamamoto, R., \& Nevins, D. J. (2001). Nondestructive measurement of kiwifruit ripeness using a laser Doppler vibrometer. Transactions of the ASAE, 44(1), 81. https://doi.org/10.13031/2013.2291

Wang, M., Sun, Y., Hou, J., Wang, X., Bai, X., Wu, C., ... \& Yang, J. (2018). A comparison of food crispness based on the cloud model. Journal of Texture Studies, 49(1), 102-112. https://doi.org/10.1111/jtxs.12295

Zhang, H., Wu, J., Zhao, Z., \& Wang, Z. (2018a). Nondestructive firmness measurement of differently shaped pears with a dual-frequency index based on acoustic vibration. Postharvest Biology and Technology, 138, 11-18. https://doi.org/10.1016/j.postharvbio.2017.12.002

Zhang, W., Lv, Z., \& Xiong, S. (2018b). Nondestructive quality evaluation of agro-products using acoustic vibration methods-A review. Critical Reviews in Food Science and Nutrition, 58(14), 2386-2397. https://doi.org/10.1080/10408398.2017.1324830 
Wangyou Zhang et al. / American Journal of Biochemistry and Biotechnology 2021, 17 (2): 232.240 DOI: 10.3844/ajbbsp.2021.232.240

Zhang, W., Cui, D., \& Ying, Y. (2015a). The impulse response method for pear quality evaluation using a laser Doppler vibrometer. Journal of Food Engineering, 159, 9-15.

https://doi.org/10.1016/j.jfoodeng.2015.03.013
Zhang, W., Cui, D., \& Ying, Y. (2015b). Orthogonal test design to optimize the acoustic vibration method for pear texture measurement. Postharvest Biology and Technology, 107, 33-42.

https://doi.org/10.1016/j.postharvbio.2015.04.002 